\title{
Over-activation of the Drosophila melanogaster hsp83 gene by selenium intoxication
}

\author{
Ronaldo Medeiros Golombieski ${ }^{1,2}$, Daniel Ângelo Sgranzerla Graichen ${ }^{2}$, João Batista Teixeira da Rocha ${ }^{1,3}$, \\ Vera Lúcia da Silva Valente ${ }^{2}$ and Élgion Lúcio da Silva Loreto ${ }^{2,4}$ \\ ${ }^{1}$ Programa de Pós-Graduação em Bioquímica Toxicológica, Universidade Federal de Santa Maria, \\ Santa Maria, RS, Brazil. \\ ${ }^{2}$ Programa de Pós-Graduação em Genética e Biologia Molecular, Departamento de Genética, \\ Universidade Federal do Rio Grande do Sul, Porto Alegre, RS, Brazil. \\ ${ }^{3}$ Departamento de Química, Universidade Federal de Santa Maria, Santa Maria, RS, Brazil. \\ ${ }^{4}$ Departamento de Biologia, Universidade Federal de Santa Maria, Santa Maria, RS, Brazil.
}

\begin{abstract}
Selenium is an important dietary micronutrient and an essential component of selenoproteins and the active sites of some enzymes, although at high concentrations it is toxic. We investigated diphenyl diselenide $\left(\left(\mathrm{C}_{6} \mathrm{H}_{5}\right)_{2} \mathrm{Se}_{2}\right)$ for its effects on the developmental stages of Drosophila melanogaster and found that in the larval and pupae stages the toxic threshold for this compound when added to the banana-agar medium on which the larva were fed was $350 \mu \mathrm{mol}$. In adult flies, fed on the same media, there were no observable toxic effects below $500 \mu \mathrm{mol}$ but there were toxic effects above $600 \mu \mathrm{mol}$, indicating that adult flies were more resistant to selenium intoxication. In larvae, a when diphenyl diselenide was present above the toxic threshold there was increased activation of the $h s p 83$ heat shock protein gene. Selenium promotes oxidation of sulfhydryl groups and affects the folding of proteins and this could explain the over-expression of $h s p 83$ because the product of this gene is involved in protein folding and defense responses, including the response to heat shock.
\end{abstract}

Key words: gene activation, $h s p 83$ gene, selenium, diphenyl diselenide.

Received: February 1, 2007; Accepted: June 11, 2007.

\section{Introduction}

Cellular responses to stress are evolutionarily ancient, ubiquitous, and essential mechanisms for the continued survival and reproduction of organisms (Lindquist, 1986; Feder and Hofmann, 1999). An important part of the cellular response to heat stress is played by a group of genes coding for heat shock proteins (HSP) or stress proteins, because their expression can be induced by high temperatures and a whole range of other stress factors (Sørensen et al., 2003; Sørensen et al., 2005). Stress responsive genes are of interest to the study and understanding of not only environmental stress resistance and stress response in general but also protein folding-mediated diseases in humans, immunological responses, animal breeding, genetic stress, protein quality control, developmental biology and gene regulation (Sørensen et al., 2005).

Send correspondence to Élgion Lúcio da Silva Loreto. Departamento de Biologia, Universidade Federal de Santa Maria, Campus Universitário, Prédio 16-A, Bairro Camobi, 97105-900 Santa Maria, RS, Brazil. E-mail: elgion.loreto@ pq.cnpq.br.
Selenium, a nonmetal related to sulfur and tellurium, has long been recognized as a dietary antioxidant and as an important dietary micronutrient in mammals (Walter et al., 1972; Combs and Combs, 1986; Leibovitz et al., 1990; May, 2002). At the molecular level, selenium is an essential component of the active sites of the enzymes glutathione peroxidase (Enzyme Commission number = EC 1.11.1.9), iodothyronine 5'-deiodinase (EC 1.97.1.10) and mammalian thioredoxin reductase (TrxR, EC 1.8.1.9) and is also present in several other mammalian selenoproteins. A deficiency in dietary selenium results in decreased levels of selenoproteins, thus compromising biological processes that are maintained by these proteins (Martin-Romero et al., 2001). Both glutathione peroxidase and TrxR catalyze reactions that are essential to the protection of cellular components against oxidative and free radical damage. As a consequence of the growing recognition of the important biological role of selenium, a number of novel pharmaceutical agents which are selenium-based or which target spe- 
cific aspects of selenium metabolism are under development (May, 1999; Meotti et al., 2004).

A variety of seleno-organic compounds are now considered as potential antioxidant and chemopreventive pharmacological agents (Commandeur et al., 2001; Klotz and Sies, 2003). Müller et al. (1984) described 2-phenyl-1,2benzisoselenazol-3(2H)-one, a synthetic lipid-soluble selenium-containing heterocyclic also known as PZ 51, DR3305 or Ebselen, which mimics glutathione peroxidase activity an which has been successfully used experimentally and pre-clinically in a variety of situations where free radicals were involved (Parnham et al., 1987; Harman et al., 1992; Kobayashi et al., 2001; Kono et al., 2001; Porciúncula et al., 2001; Rossato et al., 2002a, 2002b; Farina et al., 2003; Klotz and Sies, 2003). Diselenides are good candidates as antioxidant agents because they have some chemical and biochemical characteristics in common with Ebselen in that they exert glutathione peroxidase-like activity and can react with sulfhydryl groups to form selenosulfide (-Se-S) and disulfides, (Engman et al., 1994; Barbosa et al., 1998). Of particular importance is diphenyl diselenide $\left(\left(\mathrm{C}_{6} \mathrm{H}_{5}\right)_{2} \mathrm{Se}_{2}\right)$, the simplest of the diaryl diselenides, which has been shown to be even more active as a glutathione peroxidase mimic (Wilson et al., 1989) and less toxic to rodents than Ebselen (Meotti et al., 2003; Nogueira et al., 2003). Furthermore, diphenyl diselenide shows antiinflammatory and antinociceptive activity (Nogueira et al., 2001) and has a neuroprotective effect on in vitro models of ischemia (Ghisleni et al., 2003) and glutamate neurotoxicity (Porciúncula et al., 2001; Rossato et al., 2002a).

The fruit fly, Drosophila melanogaster, has been used for over a century as a model for probing the mysteries of genetics and biology (Ashburner, 2005; Tickoo and Russell, 2002). Comparative studies between the fly and human genomes have identified strong evolutionary conservation from insects to mammals at both sequence (structure) and pathway (function) levels (Rubin et al., 2000; Ballatori and Villalobos, 2002). The use of sophisticated genetic approaches combined with emerging genomics technologies suggest that the fly has much to offer as a tool for understanding basic cellular processes and provides an attractive and complex model system for exploring the molecular basis of human diseases such as cancer, Alzheimer's disease and Huntington's disease (Rubin et al., 2000; Tickoo and Russell, 2002).

Heat shock proteins (HSP) are members of a larger group of proteins called molecular chaperones, characterized by their ability to affect the structure or folded state of other proteins and are a family of proteins that are constitutively expressed at high level, with levels increasing when cells are stressed. The HSP include both highly conserved and more variable members, and are induced in all cells in response to heat stress (Lindquist, 1986). In Drosophila, six major HSP (Hsp-83, Hsp-70, Hsp-27, Hsp-26, Hsp-23 and Hsp-22) are induced in response to heat stress, with Hsp83 being constitutively expressed and upregulated several times during heat stress. The functions of Hsp83 include regulating the activity of other proteins such as specific steroid hormone receptor molecules (Picard et al., 1990; Parsell and Lindquist, 1993). Heat stress causes trimerization and activation of the constitutively expressed heat shock transcription factor (HSF), which is required for $h s p$ gene induction (Jedlicka et al., 1997; Westwood et al., 1991). The $h s p 83$ gene is a member of the $h s p 90$ gene family, which has been highly conserved through evolution (King and Tower, 1999).

In this paper, we describe the toxicological effect of diphenyl diselenide during different stages of the $D$. melanogaster life cycle and present $h s p 83$ transcription data on the potential of this seleno-organic compound to promote cellular stress.

\section{Material and Methods}

\section{Drosophila stock used and rearing conditions}

We obtained Drosophila melanogaster (Harwich strain) from the National Species Stock Center, Bowling Green, OH, USA. The flies were reared in $2.5 \mathrm{~cm}$ x $6.5 \mathrm{~cm}$ bottles containing $5 \mathrm{~mL}$ of cornmeal medium (Klein et al. 1999) at constant temperature and humidity $\left(20^{\circ} \mathrm{C} \pm 1{ }^{\circ} \mathrm{C}\right.$ and $60 \%$ relative humidity). Analyses of viability and developmental rate of the flies in different diphenyl diselenide molarities were performed in banana-agar medium (20\% v/v homogenized banana; $1 \%$ (w/v) brewer's yeast; $2 \%(\mathrm{w} / \mathrm{v})$ sucrose; $1 \%(\mathrm{w} / \mathrm{v})$ powdered milk; $1 \%$ $(\mathrm{w} / \mathrm{v})$ agar; and $0.08 \%(\mathrm{v} / \mathrm{w})$ methyl p-hydroxybenzoate (Nipagin $^{\circledR}$ Delaware, Brazil). Diphenyl diselenide (molecular formula $\left(\mathrm{C}_{6} \mathrm{H}_{5}\right)_{2} \mathrm{Se}_{2}$ (molar mass $312.13 \mathrm{~g} \mathrm{~mol}^{-1}$, CAS 1666-13-3). Diphenyl diselenide was synthesized according to literature methods (Paulmier, 1986) dissolved in dimethyl sulfoxide (DMSO, Sigma-Aldrich, USA) and added to the medium to produce diphenyl diselenide concentration, from 300, 350, 400, 450, 500, 600, 700, 800, 900 and $1000 \mu \mathrm{mol}\left(\mathrm{C}_{6} \mathrm{H}_{5}\right)_{2} \mathrm{Se}_{2} / \mathrm{kg}$ of medium. In the control treatment only DMSO was added to the medium.

To test egg to adult survival and developmental rate in different diphenyl diselenide molarities about 200 adult flies were transferred to a $300 \mathrm{~mL}$ empty bottle, which was inverted over a Petri dish containing banana medium to allow the flies to deposit fresh embryos. After $30 \mathrm{~min}$ the eggs were picked with a histological needle and rinsed in $0.5 \%(\mathrm{v} / \mathrm{w})$ sodium hypochloride solution, after in distilled water and transferred to medium containing the desired molarity of diphenyl diselenide. Thirty eggs were placed per bottle and observed daily to accompany the developmental stages. Five replicates were prepared per treatment.

To determine the lifespan of the adult flies when they were unexposed or exposed to diphenyl diselenide freshly ecloded flies were collected and reared on banana-agar medium containing the desired diphenyl diselenide molarities. 
For each experiment, 10 vials, each containing 5 males and 5 females, were maintained at $20^{\circ} \mathrm{C}$. Flies were transferred to new vials every 3 days. The number of dead flies was counted every day. Generally, five replicates were prepared per treatment but in some cases up to eight replicates were made.

\section{Molecular methods}

To investigate whether exposure to diphenyl diselenide induced cellular stress we estimated the transcriptional expression of the $H s p 83$ gene using the Northern blot method. Total RNA was isolated from third-instar $D$. melanogaster larvae which had been exposed to one of following treatments: i) reared completely in banana-agar medium supplemented with $300 \mu \mathrm{mol}$ of diphenyl diselenide; ii) transferred $8 \mathrm{~h}$ before RNA isolation to banana-agar medium supplemented with either 300 or $800 \mu \mathrm{mol} / \mathrm{kg}$ of diphenyl diselenide; iii) transferred $2 \mathrm{~h}$ before RNA isolation to a $30^{\circ} \mathrm{C}$ chamber to induce heat shock. A group of control larvae were reared on unsupplemented banana-agar medium. Total RNA was isolated with TRIzol ${ }^{\circledR}$ Reagent (Invitrogen Life Technologies) using 30 larvae in each treatment. Total RNA $(10 \mu \mathrm{g})$ was fractionated on $1.5 \%(\mathrm{w} / \mathrm{v})$ agarose gel in 4-(2-Hydroxyethyl)-1-piperazine-ethanesulphonic acid (HEPES)/formamide buffer and transferred to Hybond ${ }^{\circledR} \mathrm{N}+$ nylon membrane (Amersham Bioscience). The membranes were hybridized to the random primelabeled probes at $65{ }^{\circ} \mathrm{C}$ in a mixture containing $0.1 \%(\mathrm{w} / \mathrm{v})$ sodium dodecyl sulfate, $5 \%(\mathrm{w} / \mathrm{v})$ dextran sulfate and a 20 fold dilution of liquid block (Gene Image $\mathrm{Kit}^{\mathbb{B}}$ - Amersham Biosciences) in $5 \mathrm{x}$ saline-sodium citrate (SSC) buffer. The filters were washed twice at $65^{\circ} \mathrm{C}$, firstly with $1 \mathrm{x}$ SSC and $0.1 \%(\mathrm{w} / \mathrm{v})$ SDS and then with $0.2 \% \mathrm{SSC}$ and $1 \%(\mathrm{w} / \mathrm{v})$ $\mathrm{SDS}$, in both cases under agitation for $15 \mathrm{~min}$. For detection, the Gene Image CPD-Star kit (Amersham Biosciences) was used, following the manufacturer's instructions.

The phsp 83 plasmid (Straten et al., 1997) containing the D. melanogaster hsp 83 gene was used as probe. To control the quantity of RNA applied to the gel, the membrane was re-hybridized with the plasmid containing the $18 \mathrm{~S}$ rRNA sequence (Straten et al., 1997).

\section{Statistical analyses}

The Kaplan-Meier method was used to generate survival curves for all survival experiments using the SPSS 10.0 for Windows Software. Differences in survival between treatment groups were compared using the nonparametric Log-Rank test, where $p<0.05$ indicates a significant difference between experimental and control groups. The individual $\mathrm{p}$ values were adjusted for multiple testing by controlling for false discovery rate using the Benjamini and Hochberg false discovery rate method (Benjamini and Hochberg, 1995). The Northern blots were analyzed with the LabImage ${ }^{\circledR}$ Gel Analysis and Documentation System program version 2.62 ${ }^{\circ} 1999-2001$ (Kapelan GmbH, German).

\section{Results}

In the experiments to test the effects of different diphenyl diselenide molarities on D. melanogaster egg-topupae developmental rate and viability we found a molarity-dependent relationship between diphenyl diselenide concentration and the rate of development of $D$. melanogaster. As the molarity of diphenyl diselenide increased there was a delay from one to four days for larvae to reach the pupae stage (Figure 1). This data was subjected to chi-squared analysis and the Benjamini and Hochberg false discovery rate method (Benjamini and Hochberg, 1995) and the results presented in Table 1. In most cases a higher diphenyl diselenide molarity was related to a significant reduction in the viability of the flies. The exception was $300 \mu \mathrm{mol}$ diphenyl diselenide which showed a slightly increased percentage viability (89\%) compared with control flies treated with DMSO only, for which only $88 \%$ of eggs reached the pupae stage. However, viability decreased when the larvae were exposed to diphenyl diselenide molarities exceeding $300 \mu \mathrm{mol}$ (Table 1), with the pupal stage being reached by $76 \%$ of eggs exposed to $350 \mu$ mol diphenyl diselenide, $73 \%$ exposed to $400 \mu \mathrm{mol}, 37 \%$ exposed to $450 \mu \mathrm{mol}$ and only $7 \%$ exposed to $500 \mu \mathrm{mol}$. At diphenyl diselenide molarities exceeding $500 \mu \mathrm{mol}$ all larvae died. Almost all pairwise comparisons were statistically significant, the exception being the lack of significance between diphenyl diselenide molarities of $350 \mu \mathrm{mol}$ and $400 \mu \mathrm{mol}$ (Table 1).

The effect of different diphenyl diselenide molarities on the pupal stage of the D. melanogaster life cycle is

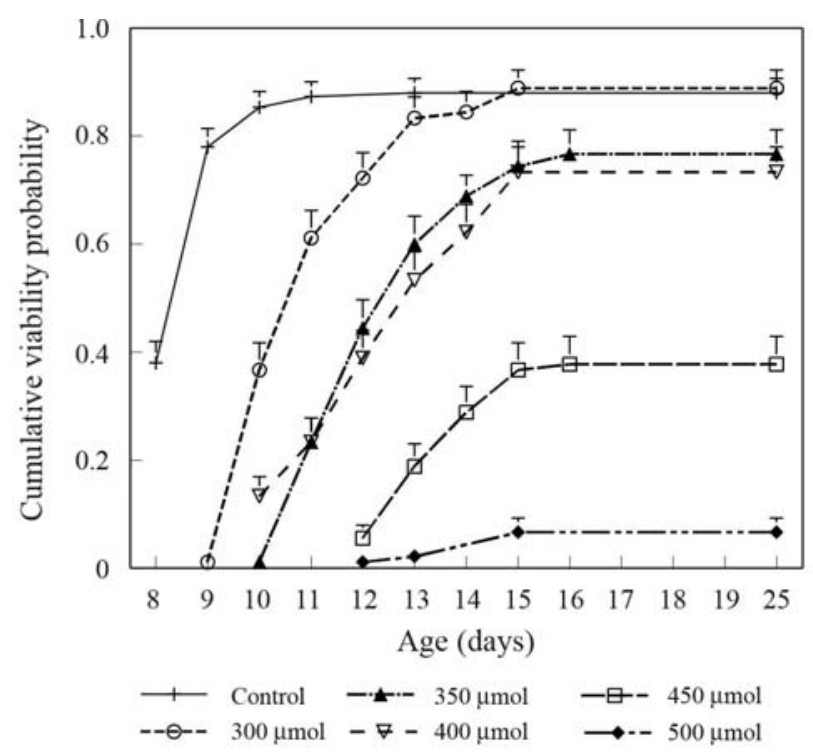

Figure 1 - Diphenyl diselenide molarity and Drosophila melanogaster viability and developmental delay curves for the egg to pupa stage. For each of five replicates, 30 eggs were placed on banana-agar containing different molarities of diphenyl diselenide and assessed for viability every day up to the pupal stage, the Y-axis representing the percentage of viable larvae surviving to this stage. 
Table 1 - Pairwise chi-squared $\left(\chi^{2}\right)$ comparisons of the D. melanogaster egg to pupae developmental rate for flies fed on banana-agar medium supplemented with different molarities ( $\mu \mathrm{mol} / \mathrm{kg}$ of medium) of diphenyl diselenide dissolved in dimethyl sulfoxide (DMSO). The comparisons use the Benjamini and Hochberg false discovery rate method and are ranked (i) in order of decreasing $\chi^{2}$ value and probability level (p) is in increasing magnitude. The corrected p-value (A) is equal to the p-value multiplied by the rank (i) and divided by the total number of comparisons $(\mathrm{A}=\mathrm{p} \mathrm{i} / 15)$ for an error rate $=0.05$. The treatments were significantly different in respect to developmental rate when $\mathrm{A}>\mathrm{p}$, with the higher diphenyl diselenide molarities showing lower development rates. The control was DMSO only and $30 \mathrm{D}$. melanogaster eggs were used for the control and each diphenyl diselenide concentration.

\begin{tabular}{lccccc}
\hline $\begin{array}{l}\text { Diphenyl } \\
\text { diselenide } \\
\text { molarity }\end{array}$ & $\chi^{2}$ & $\mathrm{p}$ & $\mathrm{i}$ & $\begin{array}{c}\mathrm{A}=0.05 \\
\mathrm{i} / 15\end{array}$ & $\begin{array}{c}\text { Significant } \\
(\mathrm{A}>\mathrm{p})\end{array}$ \\
\hline 0.00 vs. 500 & 157.11 & 0.000000 & 1 & 0.00333 & Yes \\
300 vs. 500 & 145.13 & 0.000000 & 2 & 0.00667 & Yes \\
0.00 vs. 450 & 110.90 & 0.000000 & 3 & 0.01000 & Yes \\
350 vs. 500 & 100.53 & 0.000000 & 4 & 0.01333 & Yes \\
400 vs. 500 & 90.76 & 0.000000 & 5 & 0.01667 & Yes \\
300 vs. 450 & 88.62 & 0.000000 & 6 & 0.02000 & Yes \\
0.00 vs. 400 & 59.45 & 0.000000 & 7 & 0.02333 & Yes \\
0.00 vs. 350 & 58.83 & 0.000000 & 8 & 0.02667 & Yes \\
350 vs. 450 & 38.87 & 0.000000 & 9 & 0.03000 & Yes \\
300 vs. 0.00 & 36.91 & 0.000000 & 10 & 0.03333 & Yes \\
400 vs. 450 & 30.86 & 0.000000 & 11 & 0.03667 & Yes \\
450 vs. 500 & 25.82 & 0.000000 & 12 & 0.04000 & Yes \\
300 vs. 400 & 20.20 & 0.000000 & 13 & 0.04333 & Yes \\
300 vs. 350 & 19.66 & 0.000010 & 14 & 0.04667 & Yes \\
350 vs. 400 & 0.24 & 0.623300 & 15 & 0.05000 & No \\
\hline
\end{tabular}

shown in Figure 2. In the control without diphenyl diselenide the percentage viability at this stage was $80 \%$ but the viability increased to $86 \%$ at $300 \mu \mathrm{mol}$ diphenyl diselenide, although there was an average delay of two days for the flies to complete their developmental cycle. However, at higher diphenyl diselenide molarities there was a significant decline in viability from $72 \%$ viability at $350 \mu \mathrm{mol}$ diphenyl diselenide to $3.33 \%$ viability at $500 \mu \mathrm{mol}$ (Table 2) and the development cycle increased from two to seven days as diphenyl diselenide concentration increased. At $600 \mu \mathrm{mol}$ diphenyl diselenide and above none of the pupae survived. Almost all pairwise comparisons were statistically significant, the exception being the lack of significance between diphenyl diselenide molarities of $350 \mu \mathrm{mol}$ and $400 \mu \mathrm{mol}$ (Table 2).

The adult flies were more resistant to diphenyl diselenide intoxication than larvae or pupae. Below $500 \mu \mathrm{mol}$ diphenyl diselenide there was no significant alteration to the lifespan of adult flies (data not shown). However, contrasting with the lower diphenyl diselenide molarities, there was a significant decline in the lifespan of the adult flies at molarities exceeding $500 \mu \mathrm{mol}$ when compared to the con-

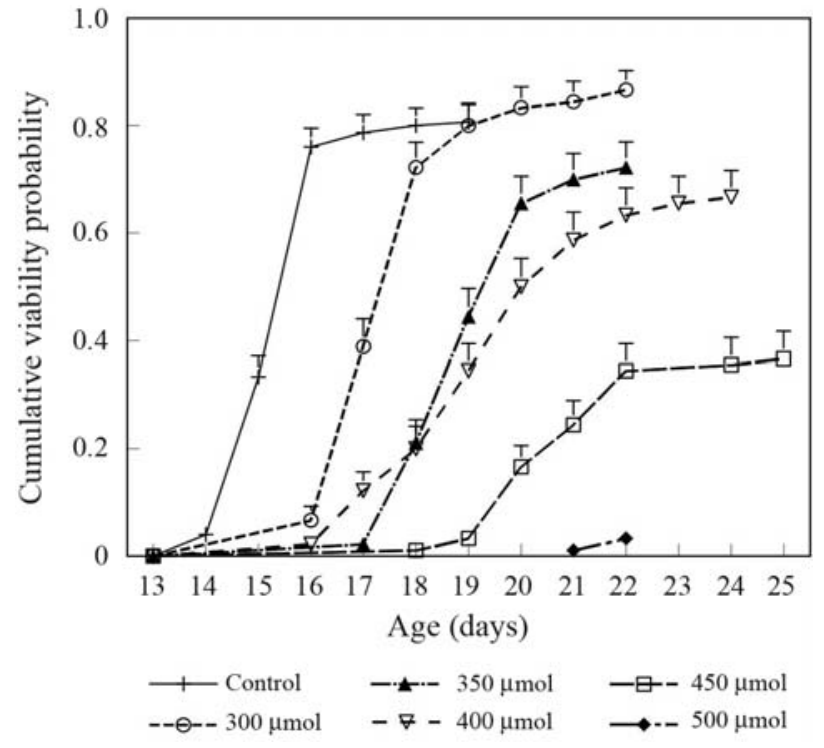

Figure 2 - Diphenyl diselenide molarity and Drosophila melanogaster viability and developmental delay curves for the pupa to adult stage. For each of five replicates, 30 eggs were placed on banana-agar containing different molarities of diphenyl diselenide and assessed for viability every day up to adulthood, the Y-axis representing the percentage of viable larvae surviving to this stage.

Table 2 - Pairwise chi-squared $\left(\chi^{2}\right)$ comparisons of the D. melanogaster pupae to adult developmental rate for flies fed on banana-agar medium supplemented with different molarities ( $\mu \mathrm{mol} / \mathrm{kg}$ of medium) of diphenyl diselenide dissolved in dimethyl sulfoxide (DMSO). The comparisons use the Benjamini and Hochberg false discovery rate method and are ranked (i) in order of decreasing $\chi^{2}$ value and probability level $(p)$ is in increasing magnitude. The corrected $\mathrm{p}$-value (A) is equal to the $\mathrm{p}$-value multiplied by the rank (i) and divided by the total number of comparisons $(\mathrm{A}=\mathrm{p} \mathrm{i} / 15)$ for an error rate $=0.05$. The treatments were significantly different in respect to developmental rate when $\mathrm{A}>\mathrm{p}$, with the higher diphenyl diselenide molarities showing lower development rates. The control was DMSO only and $30 \mathrm{D}$. melanogaster eggs were used for the control and each diphenyl diselenide concentration.

\begin{tabular}{lrcccc}
\hline $\begin{array}{l}\text { Diphenyl } \\
\text { diselenide } \\
\text { molarity }\end{array}$ & $\chi^{2}$ & $\mathrm{p}$ & $\mathrm{i}$ & $\begin{array}{c}\mathrm{A}=0.05 \\
\mathrm{i} / 15\end{array}$ & $\begin{array}{c}\text { Significant } \\
(\mathrm{A}>\mathrm{p})\end{array}$ \\
\hline 300 vs. 500 & 142.00 & 0.0000 & 1 & 0.00333 & Yes \\
0.00 vs. 500 & 129.24 & 0.0000 & 2 & 0.00667 & Yes \\
350 vs. 500 & 97.44 & 0.0000 & 3 & 0.01000 & Yes \\
300 vs. 450 & 87.93 & 0.0000 & 4 & 0.01333 & Yes \\
400 vs. 500 & 84.23 & 0.0000 & 5 & 0.01667 & Yes \\
0.00 vs. 450 & 74.03 & 0.0000 & 6 & 0.02000 & Yes \\
350 vs. 450 & 36.33 & 0.0000 & 7 & 0.02333 & Yes \\
0.00 vs. 400 & 34.64 & 0.0000 & 8 & 0.02667 & Yes \\
0.00 vs. 350 & 33.16 & 0.0000 & 9 & 0.03000 & Yes \\
450 vs. 500 & 31.78 & 0.0000 & 10 & 0.03333 & Yes \\
300 vs. 400 & 28.59 & 0.0000 & 11 & 0.03667 & Yes \\
300 vs. 350 & 27.82 & 0.0000 & 12 & 0.04000 & Yes \\
400 vs. 450 & 23.13 & 0.0000 & 13 & 0.04333 & Yes \\
0.00 vs. 300 & 16.24 & 0.0001 & 14 & 0.04667 & Yes \\
350 vs. 400 & 1.04 & 0.3077 & 15 & 0.05000 & No \\
\hline
\end{tabular}


trol group without diphenyl diselenide (Figure 3, Table 3). Between $500 \mu \mathrm{mol}$ and $1000 \mu \mathrm{mol}$ diphenyl diselenide there was, with one exception, no significant difference in the lifespan of the flies, suggesting a similar level of toxicity. The exception was that when $600 \mu \mathrm{mol}$ diphenyl diselenide was compared to the control group without diphenyl diselenide there was no statistically significant difference (Table 3 ) but there was a statistically significant difference between the $600 \mu \mathrm{mol}$ and $800 \mu \mathrm{mol}$ diphenyl diselenide molarities. These experiments were replicated five times and produced similar results (data not shown), with $500 \mu \mathrm{mol}$ diphenyl diselenide failing to produce significantly different results from the control without diphenyl diselenide in some replicates while in other replicates $600 \mu \mathrm{M}$ diphenyl diselenide failed to produce significantly different results from the control. These results suggest that the interval between $500 \mu \mathrm{mol}$ and $600 \mu \mathrm{mol}$ is the threshold at which diphenyl diselenide affects Drosophila adult lifespan. We also found that on the first five days the mortality of the adult flies exposed to various diphenyl diselenide molarities was very similar to that for unexposed control flies but, subsequently, the lifespan of the flies decreased, mainly for the flies exposed to the higher diphenyl diselenide molarities.

Northern blot analyses showed differential expression of hsp 83 in the different treatments (Figure 4). The treatments were able to increase the transcription of this gene, though not to the same intensity as heat shock treatment. Quantification of $h s p 83$ expression with the LabImage program gave a Northern blot value of $1.197 \pm 0.053$ for

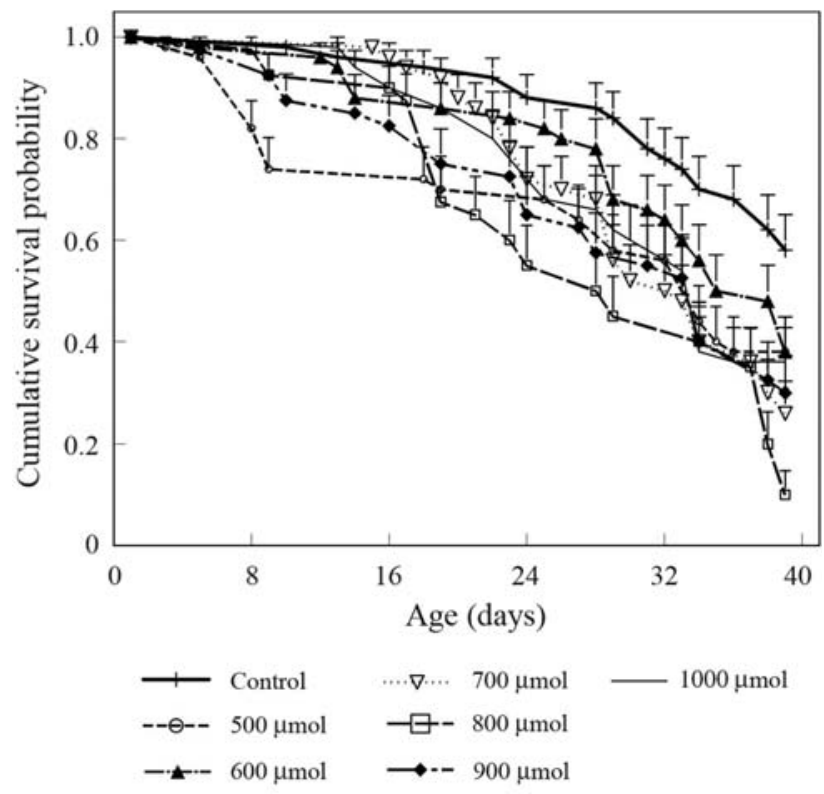

Figure 3 - Diphenyl diselenide molarities and Drosophila melanogaster adult survival curves. For each of five replicates, 30 eggs were placed on banana-agar containing different molarities of diphenyl diselenide and assessed for viability every day up to adulthood. Data are expressed as the cumulative survival probability. larvae maintained on medium containing $300 \mu \mathrm{mol}$ diphenyl diselenide and $1.421 \pm 0.051$ for larvae growing on the same medium but which were also heat shocked. In comparison, larvae maintained on medium containing $800 \mu \mathrm{mol}$ diphenyl diselenide gave a Northern blot value of $1.19 \pm 0.036$ compared with $1.604 \pm 0.021$ for larvae growing on the same medium but which were also heat-shocked. All these Northern blot values compare to an arbitrarily defined value of 1 given to the control without diphenyl diselenide. The Northern blot values for the diphenyl diselenide treatments were significantly different from control without diphenyl diselenide (both with and without heat shock treatment), suggesting that although this selenoorganic compound is able to induce a cellular stress responses the response is not as strong as that caused by heat shock.

Table 3 - Pairwise chi-squared $\left(\chi^{2}\right)$ comparisons of $D$. melanogaster adult lifespan for flies fed on banana-agar medium supplemented with different molarities $(\mu \mathrm{mol} / \mathrm{kg}$ of medium) of diphenyl diselenide dissolved in dimethyl sulfoxide (DMSO). The comparisons use the Benjamini and Hochberg false discovery rate method and are ranked (i) in order of decreasing $\chi^{2}$ value and probability level (p) is in increasing magnitude. The corrected p-value (A) is equal to the p-value multiplied by the rank (i) and divided by the total number of comparisons $(\mathrm{A}=\mathrm{p} \mathrm{i} / 21)$ for an error rate $=0.05$. The treatments were significantly different in respect to developmental rate when $\mathrm{A}>\mathrm{p}$, with the higher diphenyl diselenide molarities showing lower development rates. The control was DMSO only and 30 D. melanogaster eggs were used for the control and each diphenyl diselenide concentration.

\begin{tabular}{lccccc}
\hline $\begin{array}{l}\text { Diphenyl } \\
\text { diselenide } \\
\text { molarity }\end{array}$ & $\chi^{2}$ & $\mathrm{p}$ & $\mathrm{i}$ & $\begin{array}{c}\mathrm{A}=0.05 \\
\mathrm{i} / 21\end{array}$ & $\begin{array}{c}\text { Significant } \\
(\mathrm{A}>\mathrm{p})\end{array}$ \\
\hline 0.00 vs. 800 & 23.82 & 0.0000 & 1 & 0.0024 & Yes \\
0.00 vs. 700 & 11.71 & 0.0006 & 2 & 0.0048 & Yes \\
600 vs. 800 & 8.91 & 0.0028 & 3 & 0.0071 & Yes \\
0.00 vs. 900 & 8.88 & 0.0029 & 4 & 0.0095 & Yes \\
0.00 vs. 1000 & 6.23 & 0.0125 & 5 & 0.0119 & Yes \\
0.00 vs. 500 & 6.07 & 0.0138 & 6 & 0.0143 & Yes \\
800 vs. 1000 & 4.83 & 0.0280 & 7 & 0.0167 & No \\
0.00 vs. 600 & 3.97 & 0.0464 & 8 & 0.0190 & No \\
500 vs. 800 & 3.44 & 0.0637 & 9 & 0.0214 & No \\
700 vs. 800 & 2.71 & 0.0998 & 10 & 0.0238 & No \\
800 vs. 900 & 2.26 & 0.1328 & 11 & 0.0262 & No \\
600 vs. 700 & 2.07 & 0.1506 & 12 & 0.0286 & No \\
600 vs. 900 & 1.43 & 0.2313 & 13 & 0.0310 & No \\
700 vs. 1000 & 0.52 & 0.4721 & 14 & 0.0333 & No \\
500 vs. 600 & 0.40 & 0.5248 & 15 & 0.0357 & No \\
900 vs. 1000 & 0.37 & 0.5413 & 16 & 0.0381 & No \\
600 vs. 1000 & 0.35 & 0.5524 & 17 & 0.0405 & No \\
500 vs. 700 & 0.34 & 0.5583 & 18 & 0.0429 & No \\
800 vs. 900 & 0.16 & 0.6895 & 19 & 0.0452 & No \\
500 vs. 1000 & 0.02 & 0.8988 & 20 & 0.0476 & No \\
700 vs. 900 & 0.01 & 0.9413 & 21 & 0.0500 & No \\
\hline & & & & & \\
\hline
\end{tabular}


A
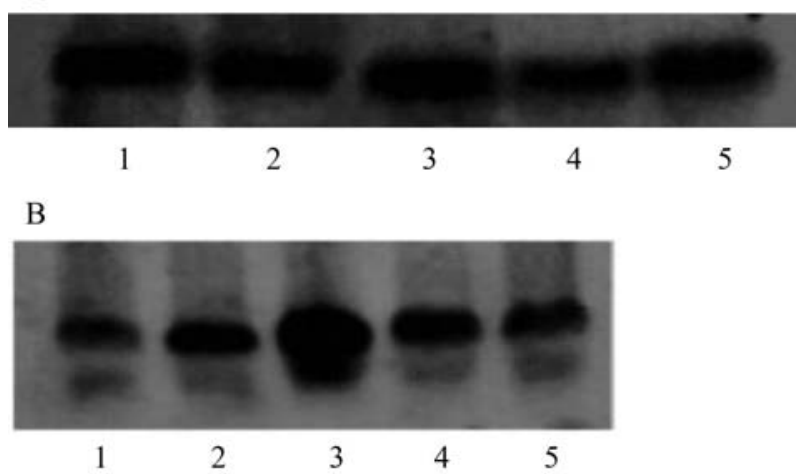

Figure 4 - Northern blot results. A) 18s ribosomal gene B) D. melanogaster hsp83 gene. Total RNA was isolated from third-instar larvae raised on banana-agar media with or without diphenyl diselenide and with or without heat shock. 1) banana-agar media containing no diphenyl diselenide (control); 2) banana-agar media containing $300 \mu \mathrm{mol}$ diphenyl diselenide; 3 ) banana-agar media containing no diphenyl diselenide and heat shocked at $30{ }^{\circ} \mathrm{C}$; 4) banana-agar media containing $300 \mu \mathrm{mol}$ diphenyl diselenide and heat shocked at $30^{\circ} \mathrm{C}$; and 5) bananaagar media containing $800 \mu \mathrm{mol}$ diphenyl diselenide.

\section{Discussion}

Selenium, while essential to the metabolism of living organisms, presents toxic effects when present at molarities higher than required in the diet. These effects could be observed in our experiments with $D$. melanogaster. The importance of selenium in D. melanogaster metabolism is indicated by the fact that when a low concentration of elemental selenium (Rosenfeld and Belth, 1964) or sodium selenite (Lewgoy and Cordeiro, 1971) was added to $D$. melanogaster culture medium there was a significant increase in the viability of the flies, although these authors also showed that high molarities of selenium decreased the viability of the flies.

The results obtained in our present work using the organic compound diphenyl diselenide, as a selenium source were consistant with those previously described by other authors (Rosenfeld and Belth, 1964; Lewgoy and Cordeiro, 1971).

In our study, $300 \mu \mathrm{mol}$ diphenyl diselenide caused a $6 \%$ increase in the viability of $D$. melanogaster larvae/pupae/adult flies, while at molarities higher than $350 \mu \mathrm{mol}$ it produced toxic effects. These results support other studies described in the literature that show that selenium is toxic to various organisms when present at molarities in excess of dietary requirements (Painter, 1941; Wilber, 1980; Yang et al., 1983; Helzisouer et al., 1985; Navarro-Alarcon and Lopez-Martinez, 2000).

Interestingly, we found that pre-adult stages were more susceptible to selenium intoxication than adult flies, with the baseline diphenyl diselenide concentration producing toxic effect in adult flies $(500 \mu \mathrm{mol})$ being lethal to larvae. This is possibly explainable by the metabolic differences between these stages, with larvae and pupae possess- ing cells undergoing active mitotic divisions while adults are post-mitotic. Affleck et al. (2006) have shown that methotrexate (an antimetabolite and antifolate used the treatment of cancer and autoimmune diseases and which acts by inhibiting folic acid metabolism) presents toxic and teratogenic effects in both larvae and pupae of drosophila but produces no such effects in adult flies, possibly because adult drosophila are post-mitotic. One explanation for such effects could be that larvae are more susceptible to selenium intoxication because they are in permanent close contact with selenium in the medium on which they are feeding. However, we observed the same toxicity pattern for pupae, which are generally on the surface of the medium and which are not actively feeding. It thus seems probable that the toxic effects of selenium in regard to drosophila pupae are probably related to ingestion and absorption of selenium during the larval stage.

In the experiments designed to investigate the effects of various diphenyl diselenide molarities on the lifespan of adult $D$. melanogaster we found that on the first five days mortality was very similar to that for control flies not exposed to diphenyl diselenide but the lifespan of the flies subsequently decreased, principally flies exposed to the higher molarities. These results were similar to those described by Leal and Neckameyer (2002) who found that there was a delay of about three days in the initiation of feeding by adult $D$. melanogaster when the gamma-aminobutyric acid (GABA) transport inhibitor DL-2,4-diaminobutyric acid (DABA) was added to their medium, possibly because the flies took around three days to start to ingest the medium. This may also have been the case for our experiments with adult flies, although it is also possible that diphenyl diselenide has a delayed effect and only acts about five five days after ingestion.

At toxic molarities we found that diphenyl diselenide induced the $h s p 83$ cellular stress response gene. The product of this gene is an $83 \mathrm{kD}$ protein reported to be involved in variouse processes, including protein complex assembly, protein folding, the defense response and the heat response (Lange et al., 2000). Several authors have shown that diphenyl diselenide promotes oxidation of sulfhydryl groups in proteins and affects the folding of these macromolecules, such oxidation also being promoted by cadmium and lead as well as selenium (Barbosa et al., 1998; Maciel et al., 2000). We suggest that activation of $h s p 83$ is an attempt by cells to recover the correct shape of proteins disturbed by high selenium molarities. It is also possible that other stress related genes involved in the refolding of proteins (e.g. hsp 70 and hsp23) could also be activated by diphenyl diselenide.

The increased viability seen by us when diphenyl diselenide was added to $D$. melanogaster culture medium below the toxic threshold concentration suggests that organic selenium compounds can be a source of necessary dietary selenium but, conversely, at levels higher than the 
threshold concentration diphenyl diselenide activates the stress responsive gene $h s p 83$ in D. melanogaster larvae. Diselenides such as Ebselen and diphenyl diselenide have been used in pre-clinical trials for their pharmacological properties but our drosophila study has shown that at high molarities these compounds can promote activation of cellular stress protection systems, indicating that further research in this area is warranted. Since cellular stress mechanisms are highly conserved, we suggest that Drosophila can be a good model for studying the effects of selenium compounds.

\section{Acknowledgments}

The authors thank Dr. Sídia Maria Callegari Jacques (Departamento de Genética, Universidade Federal do Rio Grande do Sul (UFRGS), Porto Alegre, Rio Grande do Sul, Brazil) for help with the statistical analyses and the Brazilian agencies. Dr. Gilson Zeni (Departamento de Química, Universidade Federal de Santa Maria, for diphenyl diselenide synthesis. Fundação de Amparo à Pesquisa do Estado do Rio Grande do Sul (FAPERGS grant n. 04/1196.5) and Conselho Nacional de Desenvolvimento Científico e Tecnológico (CNPq) for financial support.

\section{References}

Affleck JG, Neumann K, Wong L and Walker VK (2006) The effects of methotrexate on Drosophila development, female fecundity, and gene expression. Toxicol Sci 89:495-503.

Ashburner M (2005) Drosophila: A Laboratory Handbook and Manual. 2nd ed. Cold Spring Harbor Laboratory Press, Cold Spring Harbor, 1409 pp.

Ballatori N and Villalobos AR (2002) Defining the molecular and cellular basis of toxicity using comparative models. Toxicol Appl Pharmacol 183:207-220.

Barbosa NV, Rocha JBT, Zeni G, Emanuelli T, Beque MC and Braga AL (1998) Effect of organic forms of Selenium on aminolevulinate dehydratase from liver, kidney, and brain of adult rats. Toxicol Appl Pharmacol 149:243-253.

Benjamini Y and Hochberg Y (1995) Controlling the false discovery rate: A practical and powerful approach to multiple testing. J R Statist Soc, Series B (Methodological) 57:289-300.

Combs GF Jr and Combs SB (1986) Selenium and cancer. In: Combs GF Jr and Combs SB (eds) The Role of Selenium in Nutrition. Academic Press, San Diego, pp 413-462.

Commandeur JN, Rooseboom M and Vermeulen NP (2001) Chemistry and biological activity of novel seleniumcontaining compounds. Adv Exp Med Biol 500:105-112.

Engman L, Tunek A, Hallberg M and Hallberg A (1994) Catalytic effects of glutathione peroxidase mimetics on the thiol reduction of cytochrome c. Chem Biol Interact 93:129-137.

Farina M, Frizzo MES, Soares FAA, Schwalm FD, Dietrich MO, Zeni G, Rocha JBT and Souza DO (2003) Ebselen protects against methylmercury-induced inhibition of glutamate uptake by cortical slices from adult mice. Toxicol Lett 144:351-357.
Feder ME and Hofmann GE (1999) Heat-shock proteins, molecular chaperones, and the stress response: Evolutionary and ecological physiology. Annu Rev Physiol 61:243-282.

Ghisleni G, Porciúncula LO, Cimarosti H, Rocha JBT, Salbego CG and Souza DO (2003) Diphenyl diselenide protects rat hippocampal slices submitted to oxygen-glucose deprivation and diminishes inducible nitric oxide synthase immunocontent. Brain Res 986:196-199.

Harman AW, Adamson GM and Shaw SG (1992) Protection from oxidative damage in mouse liver cells. Toxicol Lett 64-65:581-587.

Helzisouer K, Jacobs R and Morris S (1985) Acute selenium intoxication in the United States. Proc Fed Am Soc Exp Biol 44:1670.

Jedlicka P, Mortin MA and Wu C (1997) Multiple functions of Drosophila heat shock transcription factor in vivo. EMBO J 16:2452-2462.

King V and Tower J (1999) Aging-specific expression of Drosophila hsp22. Dev Biol 207:107-118.

Klotz L and Sies H (2003) Defenses against peroxynitrite: Selenocompounds and flavonoids. Toxicol Lett 140:125-132.

Kobayashi T, Ohta Y and Yoshino J (2001) Preventive effect of ebselen on acute gastric mucosal lesion development in rats treated with compound 48/80. Eur J Pharmacol 414:271279.

Kono H, Arteel GE, Rusyn I, Sies H and Thurman RG (2001) Ebselen prevents early alcohol-induced liver injury in rats. Free Rad Biol Med 30:403-411.

Lange BMH, Bachi A, Wilm M and Gonzalez C (2000) Hsp90 is a core centrosomal component and is required at different stages of the centrosome cycle in Drosophila and vertebrates. EMBO J 19:1252-1262.

Leal SM and Neckameyer WS (2002) Pharmacological evidence for GABAergic regulation of specific behaviors in Drosophila melanogaster. J Neurobiol 50:245-261.

Leibovitz B, Hu ML and Tappel AL (1990) Dietary supplements of vitamin E, beta-carotene, coenzyme Q10 and selenium protect tissues against lipid peroxidation in rat tissue slices. $\mathrm{J}$ Nutr 120:97-104.

Lewgoy F and Cordeiro AR (1971) Ação genética e somática do selênio em Drosophila melanogaster. Cienc Cult 23:108.

Lindquist S (1986) The heat shock response. Annu Rev Biochem 55:1151-1191.

Maciel EN, Bolzan RC, Braga AL and Rocha JBT (2000) Diphenyl Diselenide and Diphenyl Ditelluride differentialy affect $\delta$-aminolevulinate dehydratase from liver, kidney and brain of mice. J Biochem Mol Toxicol 14:310-319.

Martin-Romero FJ, Kryukov GV, Lobanov AV, Carlson BA, Lee BJ, Gladyshev VN and Hatfield DL (2001) Selenium metabolism in Drosophila: Selenoproteins, selenoprotein mRNA expression, fertility, and mortality. J Biol Chem 276:29798-29804.

May SW (1999) Selenium-based drug design: Rationale and therapeutic potential. Exp Opin Invest Drugs 8:1017-1030.

May SW (2002) Selenium-based pharmacological agents: An update. Exp Opin Invest Drugs 11:1261-1269.

Meotti FC, Borges VC, Zeni G, Rocha JBT and Nogueira CW (2003) Potential renal and epatic toxicity of diphenyl diselenide, diphenyl ditelluride and Ebselen for rats and mice. Toxicol Lett 143:9-16. 
Meotti FC, Stangherlin E, Zeni G, Nogueira CW and Rocha JBT (2004) Protective role of aryl and alkyl diselenide on lipid peroxidation. Environ Res 94:276-282.

Müller A, Cadenas E, Graf P and Sies H (1984) A novel biologically active seleno-organic compound-I. Glutathione peroxidase-like activity in vitro and antioxidant capacity of PZ 51 (Ebselen). Biochem Pharmacol 33:3235-3239.

Navarro-Alarcon M and Lopez-Martinez MC (2000) Essentiality of selenium in the human body: Relationship with different diseases. The Sc Total Environ 249:347-371.

Nogueira CW, Borges VC, Zeni G and Rocha JBT (2003) Organochalcogens effects on $\delta$-aminolevulinate dehydratase activity from human erythrocytic cells in vitro. Toxicology 191:169-178.

Nogueira CW, Maciel EM, Zeni G, Graça D and Rocha JBT (2001) Biochemical toxicology of simple diorganoyl chalcogenides. ECSOC Electronic Conference on Synthetic Organic Chemistry. http://www.mdpi.net/ecsoc-5/d0013.

Painter EP (1941) The chemistry and toxicity of selenium compounds, with special reference to the selenium problem. Chem Rev 28:179-213.

Parnham MJ, Leyck S, Kuhl P, Schalkwijk J and Van Den Berg WB (1987) Ebselen: A new approach to the inhibition of peroxide-dependent inflammation. Int J Tissue React 9:4550.

Parsell DA and Lindquist S (1993) The function of heat-shock proteins in stress tolerance: Degradation and reactivation of damaged proteins. Annu Rev Genet 27:437-456.

Paulmier C (1986) Selenoorganic functional groups. In: Paulmier $\mathrm{C}$ (ed) Selenium Reagents and Intermediates in Organic Synthesis. 1st ed. Pergamon Press, Oxford, pp 25-51.

Picard D, Khursheed B, Garabedian MJ, Fortin MG, Lindquist S and Yamamoto KR (1990) Reduced levels of hsp90 compromise steroid receptor action in vivo Nature 348:166-168.

Porciúncula LO, Rocha JBT, Boeck CR, Vendite D and Souza DO (2001) Ebselen prevents excitotoxicity provoked by glutamate in rat cerebellar granule neurons. Neurosci Lett 299:217-220.

Rosenfeld I and Belth OA (1964) Selenium: Geobotany, Biochemistry, Toxicity and Nutrition. 1st edition. Academic Press, New York, 411 pp.
Rossato JI, Ketzer LA, Centuriao FB, Silva SJ, Ludtke DS, Zeni G, Braga AL, Rubin MA and Rocha JBT (2002a) Antioxidant properties of new chalcogenides against lipid peroxidation in rat brain. Neurochem Res 27:297-303.

Rossato JI, Zeni G, Mello CF, Rubin MA and Rocha JBT (2002b) Ebselen blocks the quinolinic acid-induced production of thiobarbituric acid reactive species but does not prevent the behavioral alterations produced by intra-striatal quinolinic acid administration in the rat. Neurosci Lett 318:137-140.

Rubin GM, Yandell MD, Wortmann JR, Miklos GLG, Nelson CR, Hariharan IK, Fortini ME, Li PW, Apweiler R, Fleischmann W et al. (2000) Comparative genomics of eukaryotes. Science 287:2204-2215.

Sørensen JG, Kristensen TN and Loeschcke V (2003) The evolutionary and ecological role of heat shock proteins. Ecol Lett 6:1025-1037.

Sørensen JG, Nielsen MM, Kruhøffer M, Justesen J and Loeschcke V (2005) Full genome gene expression analysis of the heat stress response in Drosophila melanogaster. Cell Stress Chaperones 10:312-328.

Straten AVD, Rommel C, Dickson B and Hafen E (1997) The heat shock protein 83 (Hsp83) is required for Raf-mediated signalling in Drosophila. EMBO J 16:1961-1969.

Tickoo S and Russell SS (2002) Drosophila melanogaster as a model system for drug discovery and pathway screening. Curr Opin Pharmacol 2:555-560.

Walter R, Schwartz IL and Roy J (1972) Can selenoamino acids act as reversible biological antioxidants? Ann N Y Acad Sci 192:175-180.

Westwood JT, Clos J and Wu C (1991) Stress-induced oligomerization and chromosomal relocalization of heat-shock factor. Nature 353:822-827.

Wilber CG (1980) Toxicology of selenium: A Review. Clin Toxicol 17:171-230.

Wilson SR and Zucker PA (1989) Development of synthetic compounds with glutathione peroxidase activity. J Am Chem Soc 111:5936-5939.

Yang G, Wang S, Zhou R and Sun S (1983) Endemic selenium intoxication of humans in China. Am J Clin Nutr 37:872-881.

Associate Editor: Carlos F.M. Menck 